\title{
Role of smokers in the household and of cardiac rehabilitation in smoking behaviour after acute myocardial infarction
}

\section{Ruolo dei fumatori nell'ambiente domestico e della Riabilitazione cardiologica nella astensione dal fumo dopo infarto miocardico}

\author{
Francesco Giallauria, Teresa Paragliola, Francesco Pilerci, Domenico Del Forno, \\ Anna De Lorenzo, Athanasio Manakos, Rosa Lucci, Marianna Psaroudaki, \\ Mariantonietta D’Agostino, Carlo Vigorito
}

\begin{abstract}
Role of smokers in the household and of cardiac rehabilitation in smoking behaviour after acute myocardial infarction. F. Giallauria, T. Paragliola, F. Pilerci, D. Del Forno, A. De Lorenzo, A. Manakos, R. Lucci, M. Psaroudaki, M. D'Agostino, C. Vigorito.

Objects: This study aims to evaluate the influence of household smokers and of a prolonged, comprehensive home-based Cardiac Rehabilitation Program (CRP) on patient's long term smoking behaviour after AMI.

Methods: 164 male post-AMI patients, all smokers until the day of AMI, were subdivided into three groups: Group $A(n=54)$ : patients with recent AMI, discharged from hospital without enrolment in CRP; Group B $(n=55)$ : similar to Group $A$ but enrolled in an 8 weeks hospital-based CRP and then discharged home with routine care; Group $C(n=55)$ enrolled in an 8 weeks hospital-based CRP followed by a further 10 months of formal home-based CRP, with scheduled hospital follow-up visits.
\end{abstract}

Results: Smoking resumption at $\mathbf{1 2}$ months was influenced by the presence of household smokers (HS): $38 \%$ of patients with HS resumed smoking compared to $27 \%$ of patients without HS $(p<0.01)$. Adherence to a CRP was inversely correlated to smoking resumption: there were fewer smoking patients at 12 months from AMI in Group C than in Groups $A$ or $B(11 \%$ in $C$ vs. $29 \%$ and $55 \%$ in $B$ and $A$, respectively, $\mathrm{p}<\mathbf{0 . 0 0 1})$.

Conclusions: Long term maintenance of CRP seems to be the best way to achieve a reduction of long term smoking habit and maintain adherence to prescription in patients after AMI. Counselling and behavioural intervention should also be extended to family members in order to maximize the benefit of secondary prevention.

Keywords: cardiac rehabilitation, secondary prevention, smoking behaviour.

Monaldi Arch Chest Dis 2005; 64: 110-115.

Department of Clinical Medicine, Cardiovascular and Immunological Science, University of Naples "Federico II", via S. Pansini 5, I-80131 Napoli (Italy).

Corresponding author: Prof Carlo Vigorito, Cardiac Rehabilitation Unit, University of Naples Federico II School of Medicine, via S. Pansini 5, I-80131 Napoli (Italy); E-mail address: vigorito@unina.it

It is well established that lifestyle plays a key role in development of coronary artery disease (CHD) ${ }^{1}$ and that smoking in particular is a critical risk factor for CHD. ${ }^{2}$ The relative risk of death from cardiovascular disease in smokers is roughly doubled compared to non-smokers, and smoking cessation significantly reduces the risk of cardiac events, in particular in patients recovering after acute myocardial infarction (AMI). ${ }^{3-5}$

Cardiac Rehabilitation Programs (CRPs) after AMI include specific interventions for reducing the cardiovascular risk profile, 6 with the aim to reduce short and long-term mortality and morbidity. 7,8

Within the CRP, psychological and behavioural interventions based on interviews, health education and psychological support are effective in reducing coronary risk factors including patients' smoking behaviour. ${ }^{9}$ However, the efficacy of standard CRP in reducing smoking behaviour is not ideal, due to incomplete success and/or long term relapse. ${ }^{9}$ The available evidence suggests that one important bar- rier to successful long term smoking cessation by cardiac patients may be the presence of smoking members in the household.10,11

The present study aims at evaluating the role of the household environment (as regards presence or not of smoking members) and the effect of two levels of CRP (standard or prolonged) in achieving smoking cessation or long-term no-relapse in patients after AMI.

\section{Methods}

This was a retrospective study that included post AMI patients derived from our records and subdivided in terms of their participation or not in a formal CRP and the duration of the CRP, standard or prolonged. The patients still under our observation (Group C) were seen at the hospital. The patients who were not under long-term observation (Groups A and B) were selected from our records and questioned by telephone. This study included 164 male 
patients with recent AMI, all smokers until the day of AMI, subdivided into subgroups according to whether or not they participated in a CRP, and the type and duration of CRP. We also subdivided patients according to the presence or not of family members who smoke in their household. In all patients we investigated smoking behaviour in the 12 months following AMI.

We divided patients into three groups. Group A $(n=54)$ consisted of cardiac patients with recent AMI discharged from hospital without enrolment in a formal CRP. Group B $(n=55)$ comprised cardiac patients with recent AMI enrolled in an 8 weeks hospital-based CRP and then discharged home without formal instructions to continue CRP. Group C $(n=55)$ consisted of patients with recent AMI enrolled in an 8 weeks hospital-based CRP, who then underwent a 10 months structured home-based CRP, with scheduled hospital follow up. There was no baseline difference between the three groups (age, sex, demographic or clinical status) [table 1].

In-hospital CRP, performed by Group B and C patients in a Day-Hospital régime, consisted in an 8 weeks multidisciplinary intervention, including 30 minutes of aerobic training with cyclette, 3 times/week, at $75 \%$ of maximum heart rate achieved during an exercise stress test performed at enrolment. Individually-tailored sessions of health education, dietetic and behavioural recommendations were carried out during the hospital stay. In particular, an individual and group counselling program for smoking cessation (see text below) based on an evaluation of motivation to refrain from smoking and on a self-evaluation test, was performed in group B and C patients. Subsequently, smoking behaviour was analyzed and discussed with the patient in follow-up hospital visits only in Group $\mathrm{C}$ patients, and further interventions to support patient motivation were performed according to the program described below.

Additionally, in Group C patients aerobic exercise training was continued for an additional 10 months in a home-based program, centered on specific questionnaires to evaluate physical training performed at home. Patients were instructed before discharge to perform exercise training, 2-3 times/week, with 30 min sessions by cyclette at the same target heart rate reached in hospital, achieved by self heart rate evaluation or by a heart rate meter. This homebased program was integrated with periodical hospital check-ups, once or twice weekly, including a session of cyclette aerobic training at the same work load previously achieved. In this setting we also strengthened psychological support to quit smoking and administered specific questionnaires to assess patients' smoking habits and attitude towards smoking. According to the protocol described below, at 10 months from discharge a questionnaire to assess the patient's smoking habits, smoking habits of others in the household and the patient's attitudes towards smoking was administered to all study patients.

\section{Program of behavioural modification, individual and group counselling for smoking cessation}

Counselling, aimed at changing patients' behaviour, thoughts and emotions $12-14$, had the following focus: ${ }^{15-17}$ to give time for contemplation, set goals, enable the patient to admit their addiction and need for help, explore with the patient stress-related circumstances/situations, plan interruption of conditioned responses that support smoking, identify and prepare plans to cope with temptations that might trigger falls, encourage self-management strategies in relation to coping with pressure to resume smoking, foster self-worth/confidence, and teach means to seek support from family, friends and coworkers. Participants' willingness to follow intervention guidelines and active participation in group-work was encouraged. Development of group cohesion was encouraged. Contact times during the follow-up period were made known beforehand and participants were told that they could contact one of the staff members by phone at any time during the intervention.

\section{Statistics}

Descriptive statistics are given in terms of means, standard deviation, frequencies and percentages. Chi-square analysis was used to test for differences with discrete categorical data. Statistical significance was set at 0.05 . Student's T Test was used to test independent samples.

\section{Results}

Ninety-seven of 164 patients $(59.1 \%)$ lived in a household in which at least one member smoked. The single most common smoker in the household was the patient's wife $(22.6 \%)$, followed by son $(8.5 \%)$, son and daughter $(7.3 \%)$ and daughter $(5.5 \%)$ [table 2]. Fifty-two of 164 patients (32\%) resumed smoking after the acute cardiovascular event.

Table 1. - Demographic and clinical data of study patients

\begin{tabular}{cccccccccccc}
\hline Group & $\begin{array}{c}\text { Patients } \\
(\mathrm{n})\end{array}$ & $\begin{array}{c}\text { Age } \\
(\text { years }) \\
(\mathrm{M} \pm \mathrm{SD})\end{array}$ & $\begin{array}{c}\text { Educational } \\
\text { Level } \\
\text { (years })\end{array}$ & $\begin{array}{c}\text { AMI } \\
\text { anterior } \\
\mathrm{n}(\%)\end{array}$ & $\begin{array}{c}\text { Diabetes } \\
\mathrm{n}(\%)\end{array}$ & $\begin{array}{c}\text { Hypertension } \\
\mathrm{n}(\%)\end{array}$ & $\begin{array}{c}\text { Regular } \\
\text { Physical } \\
\text { Activity } \\
\mathrm{n}(\%)\end{array}$ & $\begin{array}{c}\text { Total } \\
\text { Cholesterol } \\
\mathrm{mg} / \mathrm{dl} \\
(\mathrm{M} \pm \mathrm{SD})\end{array}$ & $\begin{array}{c}\text { LDL-Chol } \\
\mathrm{mg} / \mathrm{dl} \\
(\mathrm{M} \pm \mathrm{SD})\end{array}$ & $\begin{array}{c}\text { HDL-Chol } \\
\mathrm{mg} / \mathrm{dl} \\
(\mathrm{M} \pm \mathrm{SD})\end{array}$ & $\begin{array}{c}\text { Triglicerides } \\
\mathrm{mg} / \mathrm{dl} \\
\mathrm{M} \pm \mathrm{SD})\end{array}$ \\
\hline $\mathrm{A}$ & 54 & $57.6 \pm 8.2$ & 8.0 & $32(60)$ & $12(22)$ & $35(65)$ & $14(25)$ & $187 \pm 28$ & $111 \pm 50$ & $35 \pm 11$ & $177 \pm 104$ \\
\hline $\mathrm{B}$ & 55 & $58.7 \pm 9.4$ & 8.72 & $30(55)$ & $7(13)$ & $39(70)$ & $15(27)$ & $192 \pm 35$ & $106 \pm 53$ & $35 \pm 8$ & $169 \pm 79$ \\
\hline $\mathrm{C}$ & 55 & $58 \pm 7.8$ & 9.8 & $34(62)$ & $10(18)$ & $34(62)$ & $11(20)$ & $195 \pm 39$ & $121 \pm 12$ & $33 \pm 8$ & $172 \pm 69$ \\
\hline
\end{tabular}


Table 2. - Smoke distribution in the household

\begin{tabular}{lcc}
\hline & \multicolumn{2}{c}{ Household smokers } \\
& $\mathbf{n}$ & $\mathbf{\%}$ \\
\hline None & 67 & 40.9 \\
Daughter & 9 & 5.5 \\
Son & 14 & 8.5 \\
Son + Daughter & 12 & 7.3 \\
Wife & 37 & 22.6 \\
Wife + Daughter & 1 & 0.6 \\
Wife + Son & 10 & 6.1 \\
All family members & 14 & 8.5 \\
TOTAL & $\mathbf{1 6 4}$ & $\mathbf{1 0 0}$ \\
\hline
\end{tabular}

Figure 1 shows that resumption of smoking was influenced by the presence in the household of smokers: 25 of 66 patients (38\%) with a smoking member in the household had resumed smoking at 12 months, compared to $27 / 98$ (27\%) of patients without a smoking member in the household $(\mathrm{p}<0.01)$.

Adherence to the CRP also influenced, inversely, smoking resumption. There were fewer patients who resumed smoking at 12 months from AMI in group C $(6 / 55,11 \%)$ than in group $\mathrm{A}(30 / 54,55 \%$; $\mathrm{p}$ $<0.0001)$ or in group B $(16 / 55,29 \%$; $\mathrm{p}<0.001)$ [figure 2]. There were also fewer patients who resumed smoking in group B compared to A $(\mathrm{p}<0.002)$. From figure 3 it can be seen that the difference in the number and percentage of household smoking members in groups A, B, C was not significant.

Figure 4 shows, within patients of groups $\mathrm{A}, \mathrm{B}$ and $\mathrm{C}$ who were smokers at 12 months, the percentage of patients who had smoking members present in the household. There was a significantly lower percentage of smoking household members in the group A patients who resumed smoking (11 patients out of $30,36 \%$ ) than in the group C patients who resumed smoking (5 of 6 patients, 83\%) (A vs. C: $\mathrm{p}<0.0001$ ), with an intermediate value in group $\mathrm{B}$.
Figure 5 shows the global trend of smoking resumption in all groups over the 12 months. The trend gradually increased in group A patients but was stable in group $C$ patients, while there was an intermediate trend in group B patients.

\section{Discussion}

Comprehensive Cardiac Rehabilitation consists of multiple interventions that have been shown to have favourable effects after AMI, particularly in increasing functional capacity and quality of life and in improving psychological and behavioural status and coronary risk profile. 6

Concerning smoking habit, educational intervention and psychological and behavioural support are part of a multi-comprehensive CRP for reducing resumption of smoking in the long term after an acute cardiovascular event. 9

Our study demonstrates that in patients participating in a comprehensive long-term CRP, including psychological and educational support (Group C), the percentage of smoking resumption at 12 months after AMI was lower than in patients not participating in CRP (Group A) or in those who followed a standard 8 weeks CRP (Group B) [figure 2].

Since tobacco smoking is a critical risk factor for mortality and morbidity in patients after AMI, 18 the reduced percentage of long term tobacco smokers among patients enrolled in CRP may have a very favourable impact on long-term mortality and morbidity of these patients. Comprehensive CRP has been shown to reduce long-term cardiovascular mortality and morbidity,7,8 but the relative favourable role of risk factor reduction and physical training is unknown.

Our study confirms that, in order to promote optimal long-term reduction of coronary risk factors, multi-comprehensive interventions such as those included in our CRP need to be continued long term as in our patients of Group C. Group B patients, who participated in an 8 weeks CRP but were not followed

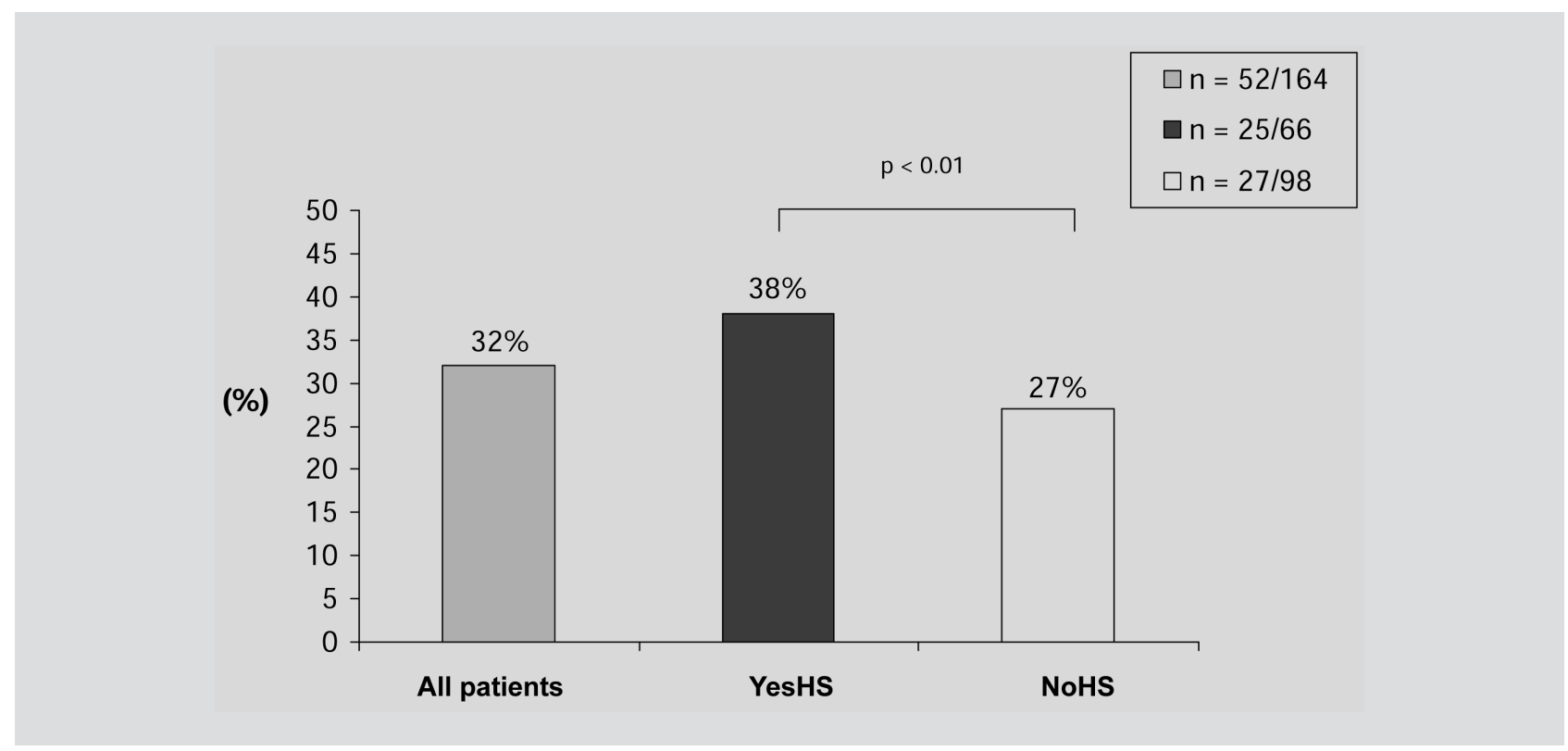

Figure 1. - Percentage of patients resuming smoking with (Yes HS) or without (No HS) presence of a smoker in the household. 


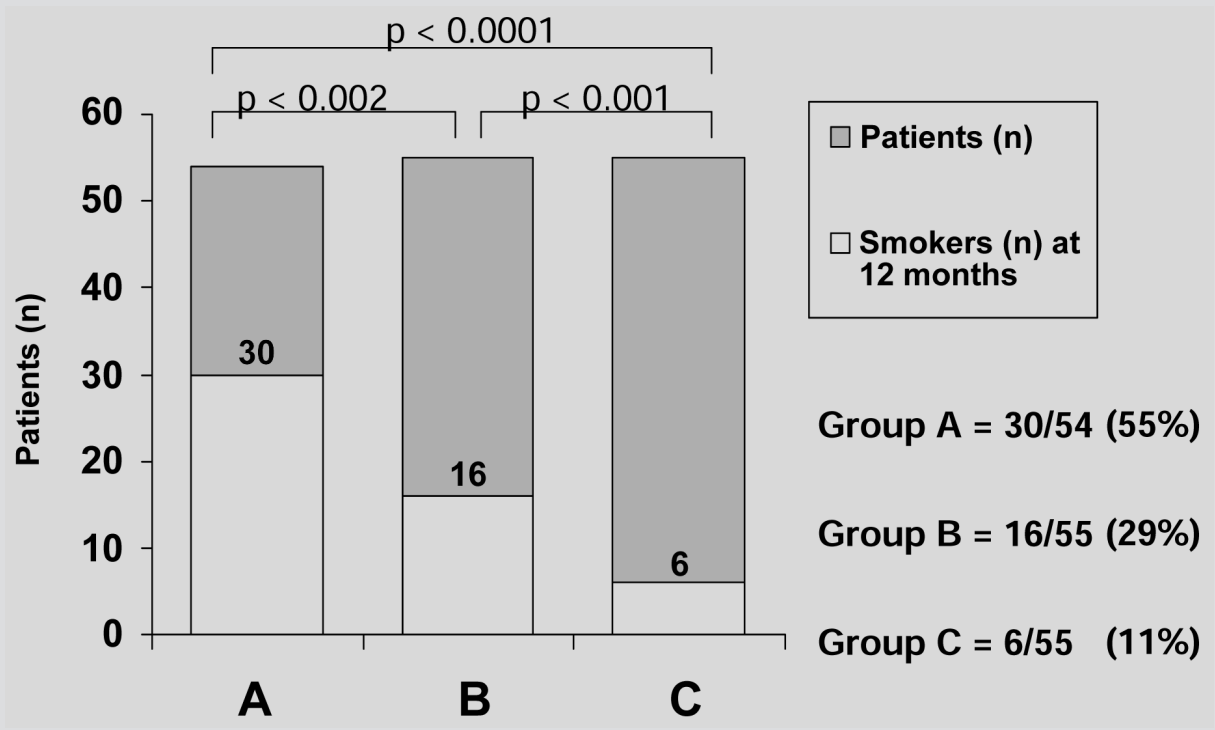

Figure 2. - Number and percentage of patients resuming smoking according to study group. Abbreviations: Groups A, B, C, see Text - Methods.

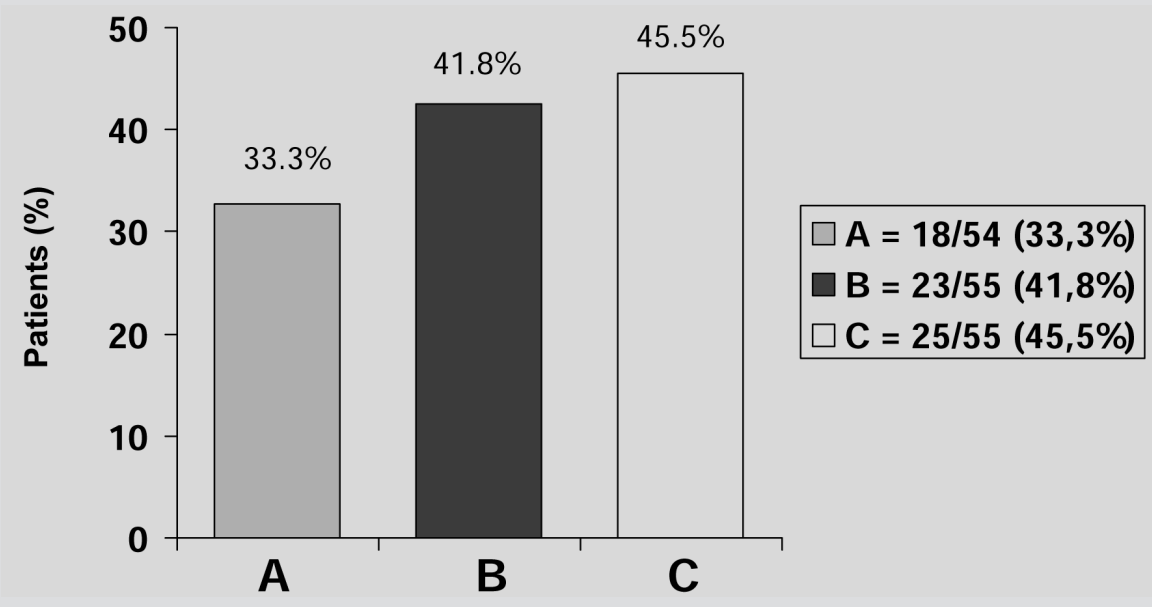

Figure 3. - Percentage of smokers in the household in Groups A, B, C. Abbreviations: as in figure 2.

in the long term, derived a reduced long term benefit from the CRP compared to Group C patients, since the rate of smoking recurrence, although lower than in Group A, was higher than that of Group C [figure 2]. Specific programs based on education and counselling and maintained level of fitness are protective against smoking recurrence, reinforcing patients' persistence in their will to abstain from smoking.9,19

On the other side, the presence of a smoking member in the household may attenuate the beneficial results of CRP, inducing the patients to resume smoking. 10,11 In our study, 59\% of patients discharged home after an AMI had at least one smoking member in the household, and this factor was associated with a significantly higher percentage of patients who resumed smoking [figure 1]. Almost all patients in Group C who resumed smoking (5/6 (83\%) had a member in the household who smoked [figure 4].
However, the presence of a household smoker does not completely nullify the advantages of CRP, particularly when CRP is continued long term. In fact, the percentage of smoking members in the household (Yes HS) was similar in Groups A, B and $\mathrm{C}$ [figure 3], with a trend to a greater number of smoking household members in Group C. The fact that it was Group $\mathrm{C}$ who showed the best rate of abstinence from smoking testifies to the benefit of participation in a long-term CRP.

Our study confirms data in the literature showing the beneficial effects of CRP on long term smoking habit. ${ }^{19}$ The behavioural and educational part of this program seems to play the most relevant role in this beneficial long term effect, although we cannot exclude that the physical training component of CRP may also have played a role. Physical exercise has in fact been described as reducing the rate of 


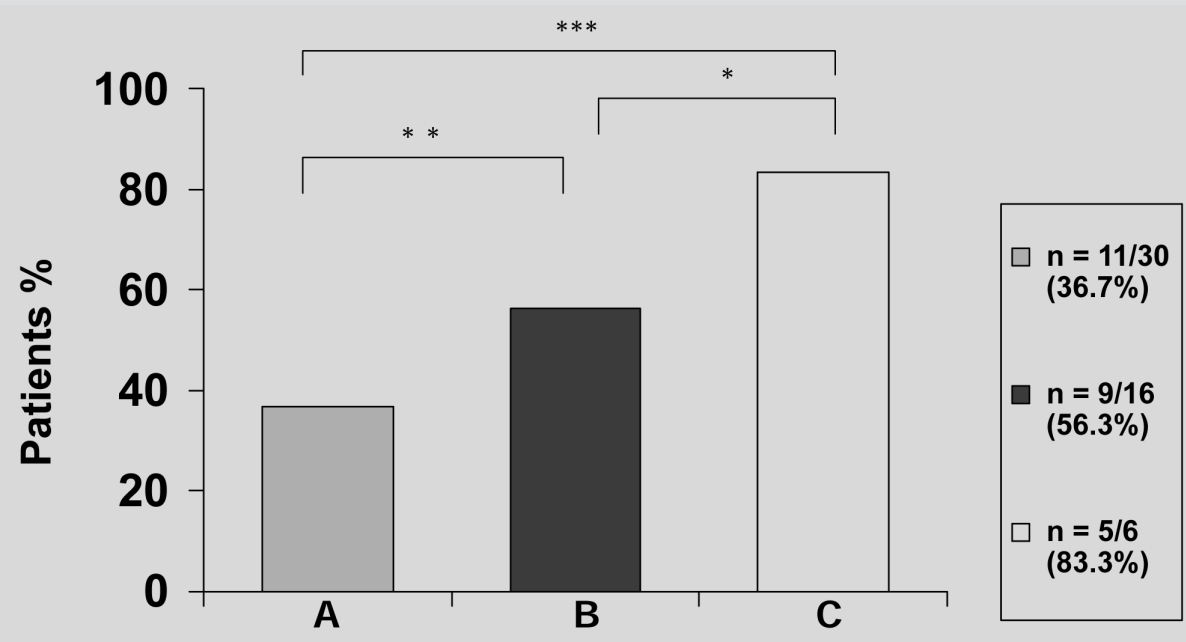

GROUP

${ }^{*} \mathrm{p}<0.001^{* *} \mathrm{p}<0.002{ }^{* * *} \mathrm{p}<0.0001$

Figure 4. - Percentage of patients who had smokers in the household among patients who resumed smoking, subdivided according to study group (Groups A, B, C). Abbreviations: as in figure 2.

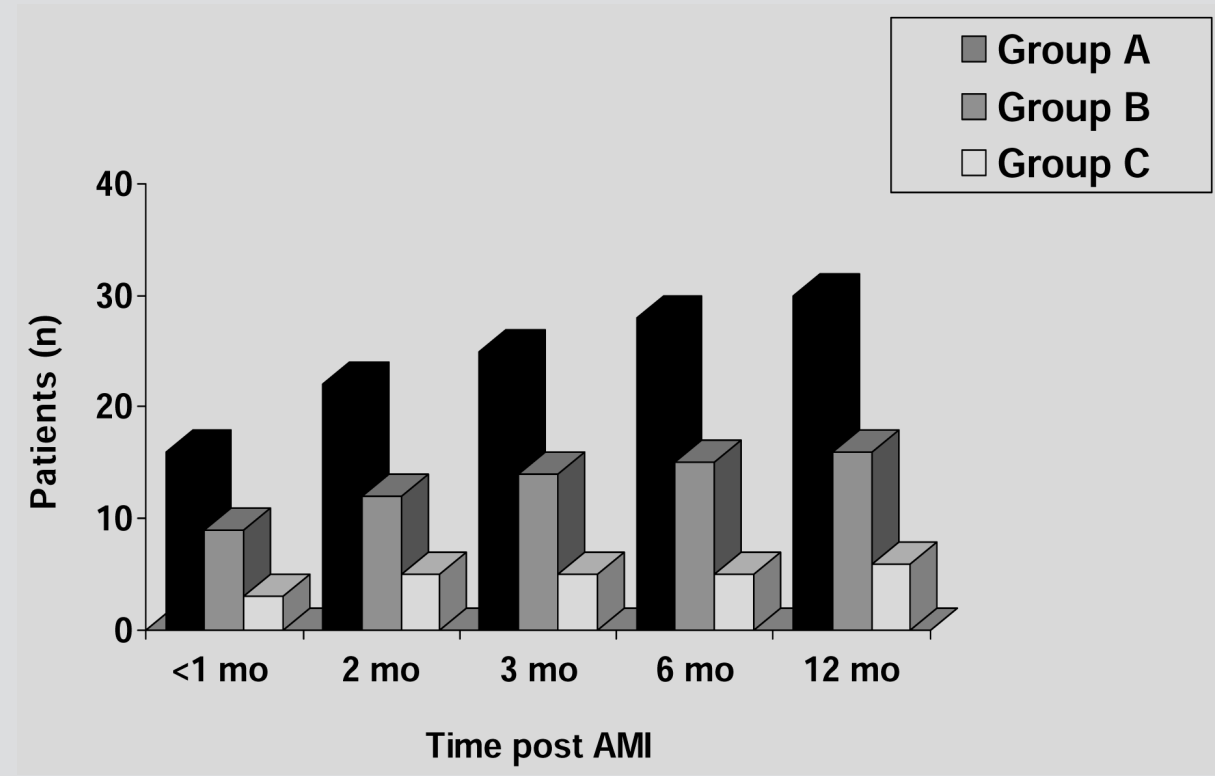

Figure 5. - Cumulative number of patients resuming smoking according to timing after AMI and study group. Abbreviations: AMI, acute myocardial infarction; Groups: A, B, C as in figure 2; mo, months.

smoking resumption. 19 Our study provides further support to the desirability of including other members of the patients' household in the educational and counselling program, since the presence of a smoking member in the household may reduce the beneficial effect of long term CRP. In fact, of the few patients of Group $\mathrm{C}$ who resumed smoking, $83 \%$ had a smoking member in the household [figure 4]. Thus, the "weight" of the presence of a smoking household member is higher in this subset of patients, and it is reasonable to believe that, with- out this interfering factor, all Group C patients would have been non smokers at 12 months.

Our study also confirms the observation that standard CRP may lose its beneficial effect gained after 8 weeks if this is not supported with some form of long-term maintenance of care. However, this observation should encourage Cardiac Rehabilitation Centres to prolong long term care rather than discourage these programs, since even "standard" CRP had some beneficial effect at 12 months, although lower than that of long-term CRP. 


\section{Study limitations}

A number of limitations of the present study need to be underlined. Whilst the sample is representative of the cardiac rehabilitation population at our Centre, sample size is quite limited and clearly the study needs to be replicated in a prospective mode and in a larger patient population. Furthermore, the retrospective nature of this study ruled out the possibility of having the Fagenstrom test available in all patients.

In addition, to verify the real abstinence of smoking, the present study used a questionnaire and not objective methods such as $\mathrm{CO}$ expired or plasma cotinine.

However, despite its limitations, our study provides useful data to encourage smoking cessation programs within CRP after AMI, and stresses the significant role of smoking household members.

In conclusion, long-term maintenance of CRP including education, counselling and physical training seems to be the best way to achieve a reduction of long-term smoking habit and maintain adherence to prescription and behavioural counselling in patients after AMI. Counselling and behavioural intervention should also be extended to household members in order to maximize the benefit of secondary prevention in these high risk patients.

\section{Riassunto}

Razionale: Scopo del seguente lavoro è quello di valutare il ruolo dell' ambiente familiare e del programma di Riabilitazione Cardiologica (PRC) sull'abitudine al fumo durante 12 mesi dopo IMA.

Materiali e metodi: 164 pazienti di sesso maschile, fumatori fino al giorno dell' IMA, sono stati suddivisi in tre gruppi. Gruppo A $(n=54)$ : infartuati dimessi senza indicazione a PRC; Gruppo $B$ $(n=55)$ : infartuati arruolati in un PRC ospedaliero di 8 settimane e poi dimessi con indicazioni di routine; Gruppo $C(n=55)$ : infartuati arruolati in un PRC ospedaliero di 8 settimane seguito da un ulteriore PRC domiciliare della durata di 10 mesi con follow-up ospedaliero programmato.

Risultati: a 12 mesi, la ripresa del fumo era influenzata dai familiari fumatori (FF) (38\% dei pazienti con FF vs. $27 \%$ dei pazienti senza FF) ( $p<0.01)$. L'adesione a PRC era correlata alla ripresa del fumo: $11 \%$ nel Gruppo C vs. $29 \%$ e $55 \%$ nei Gruppi B e A rispettivamente, $p<0.001$.

Conclusioni: il mantenimento a lungo termine del PRC risulta essere la migliore strategia per evitare la ripresa del fumo e garantire l'aderenza alle prescrizioni del PRC. Il counselling e l'intervento sulle abitudini e lo stile di vita potrebbe essere esteso ai familiari dei cardiopatici al fine di massimizzare gli effetti della prevenzione secondaria.

Parole chiave: riabilitazione cardiologica, prevenzione secondaria, abitudine al fumo.

Acknowledgments: We thank Mr. Mario Aurino, Mr. Mario Rosario Eliseo and Mrs. Maria Calabrese for their technical support and Ing. Giuseppe Quaremba for statistical analysis.

\section{CAPTIONS}

CHD: coronary heart disease

AMI: acute myocardial infarction

CRP: cardiac rehabilitation program

\section{References}

1. Critchley JA, Capewell S. Mortality risk reduction associated with smoking cessation in patients with coronary heart disease: a systematic review. JAMA 2003; 290: 86-97.

2. Fowler G. Tobacco and cardiovascular disease. Achieving smoking cessation. In: Yusuf S, Cairns JA, Camm AJ, Fallen EL, Gersh BJ. Evidence based cardiology. London: BMJ Books; 1998. pp. 179-190.

3. Daly L. Long term effect on mortality of stopping smoking after unstable angina and myocardial infarction. $\mathrm{Br}$ Med J 1983; 287: 324-326.

4. Aberg A, Bergstrand R, Johansson S, Ulvenstam G, Vedin A, Wedel H, Wilhelmsson C, Wilhelmsen L. Cessation of smoking after myocardial infarction. Effects on mortality after 10 years. Br Heart J 1983; 49: 416-22.

5. Mulcahy R. Influences of cigarette smoking on morbidity and mortality after myocardial infarction. Br Heart $J$ 1983; 49: 410-15.

6. Ades PA. Cardiac Rehabilitation and secondary prevention of coronary heart disease. $N$ Eng J Med 2001; 345: 892-902.

7. Oldridge NB, Guyatt GH, Fischer ME, Rimm AA. Cardiac rehabilitation after myocardial infarction. Combined experience of randomized clinical trials. J Am Med Ass 1988; 260: 945-50.

8. O' Connor GT, Buring JE, Yusuf S, Goldhaber SZ, Olmstead EM, Paffenbarger RS Jr, Hennekens CH. An overview of randomized trials of rehabilitation with exercise after myocardial infarction. Circulation 1989; 80: 234-44.

9. Taylor CB, Houstom-Miller N, Killen JD, DeBusk RF. Smoking cessation after acute myocardial infarction: effects of a nurse-managed intervention. Ann Intern Med 1990; 113: 118-23.

10. Hevey D, Slack K, Cahill A, Newton H, Horgan JH. Rates of smoking in the households of cardiac patients. $J$ Cardiovasc Risk 2002; 9: 271-274.

11. Ashley MJ, Cohen J, Ferrence R, Bull S, Bondy S, Poland B, Pederson L. Smoking in the home: changing attitudes and current practices. Am J Public Health 1998; 88: 797-800.

12. Marlatt GA, Gordon JR. Relapse prevention: maintenance strategies in the treatment of addictive behaviours. New York: Guidford Press; 1985.

13. Coleman KJ, Raynor HR, Mueller DM, Cerny FJ, Dorn JM, Epstein LH. Providing sedentary adults with choises for meeting their walking goals. Prev Med 1999, 28: 510-519.

14. American College of Sports Medicine. American College of Sports Medicine Guidelines for Exercise Testing and Prescription, 6th edn. Philadelphia, PA: Williams \& Wilkins; 2000.

15. Silagy C, Lancaster T, Stead L, Mant D, Fowler G. Nicotine replacement therapy for smoking cessation. Cochrane Database Syst Rev 2004; (3): CD000146.

16. Sallis JF, Haskell WL, Fortmann SP, Vranizan KM, Taylor CB, Solomon DS. Predictors of adoption and maintenance of physical activity in a community sample. Prev Med 1986;15: 331-341.

17. Borg G. Borg's perceived exertion and pain scales. Champaign, IL: Human Kinetics; 1998.

18. Smoking attributable mortality in years of potential life lost - United States, 1998. Morb Mortal Wkly Rep 1991; 40: 62-63, 69-71.

19. Clavario P. Ruolo dell'esercizio fisico nei programmi di trattamento del tabagismo. Ital Heart J 2001; 2 (Suppl 1): 101-103. 